\section{A NOTE ON THE RESULTS OBTAINED BY THE ANTI-TYPHOID INOCULATIONS IN THE BELEAGUERED GARRISON \\ IN LADYSMITH.}

BY A. E. WRIGHT, M.D. DUB.,

PROFHSSOR OF PATHOLOGY, ARMY MEDICAL SCHOOL, NETLEY.

BY the kind permission of Surgeon-General Jameson, M.D., C.B., I am enabled to publish the following officially collected statistics with regard to the results obtained by the anti-typhoid inoculations in the military garrison during the siege of Ladysmith.

TABLE I.-Results obtained by the Anti-Typhoid Inoculations in the Case of the Officers and Men of the Military Garrison during the Siege of Ladysmith.

\begin{tabular}{|c|c|c|c|c|c|c|}
\hline & 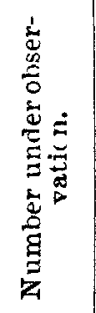 & 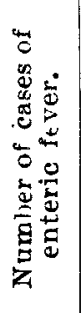 & 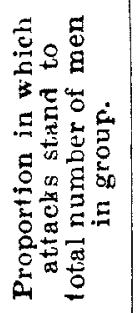 & 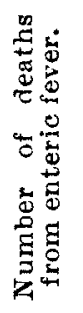 & 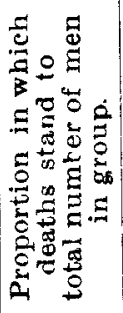 & 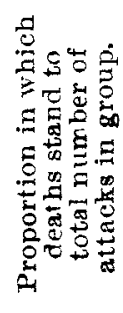 \\
\hline Not inoculated & 10,529 & 1489 & 1 in 707 & 329 & 1 in 32 & 1 in 4.52 \\
\hline Inoculated $\ldots$ & 1,705 & 35 & 1 in 48.7 & 8 & 1 in 213 & 1 in 4.4 \\
\hline
\end{tabular}

In addition to the above summary of results, obtained on officers and men combined, the figures relating to officers separately are also given in the official statistics. With regard to these last it may be pointed out that quite apart from the fact that these figures relate to a very small group of persons ( 44 in number) the figures considered as statistics are probably fallacious owing to the fact that the group of inoculated officers (consisting as it must have done almost exclusively of young men at the most susceptible age) is compared with a group of officers which includes all the older and less susceptible men and the men who have already had typhoid fever. The figures referred to are none the less subjoined with a view to conforming to the arrangement adopted in the official statistics.

TABLE II.-Results obtained by the Anti-Typhoid Inoculations in the Case of the Officers of the Military Garrison during the Siege of Ladysmith.

\begin{tabular}{|c|c|c|c|c|c|}
\hline - & 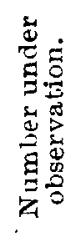 & 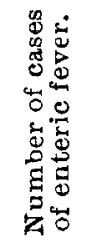 & 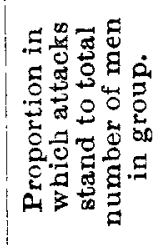 & 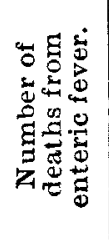 & 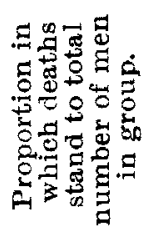 \\
\hline Not inoculated ... & 171 & 43 & 1 in 4 & 5 & 1 in 34.2 \\
\hline Inoculated $\ldots . .$. & 44 & 9 & 1 in 5 & 2 & 1 in 22 \\
\hline
\end{tabular}

In drawing inferences from the figures in this table it is to be borne in mind that the erroneous inclusion or exclusion of a single case, or a difference in the event in the case of any patient included in the category of the inoculated, would sensibly alter the present aspect of the table.

The same circumstance must be borne in mind in connexion with any attempt to base a comparison of the rase mortality in inoculated and uninoculated upon the figures in Table I. For it will be manifest that in no circumstances can an estimate of case mortality be safely based on a series of only 35 cases, and least of all would it be permissible to do this under conditions such as those of Ladysmith during the siege, where many other factors in addition to the severity of the attack must have determined the favourable or unfavourable event of the cases. It would, however, appear probable, in view of the figures given in the table, that the case mortality was not influenced by the inoculation. On this subject further light must be awaited, especially as it would appear from certain statements which have emanated from the seat of war that the disease generally runs a milder course in the inoculated.

The question of case mortality is, however, quite subordinate in interest to the question as to how far the figures presented in Table I. enable us to estimate in quantitative terms the reduction in incidence and mortality which can be achieved by the process of anti-typhoid inoculation.

To answer this question it will be necessary to inquire, on the one hand, whether there were any circumstances other than inoculation which may have tended, either to diminish the incidence of typhoid fever among the inoculated in Ladysmith, or unduly to swell the roll of typhoid fever among the inocalated.

In connexion with the former question the only point which comes up for consideration is the question as to whether the inoculated were more favourably circumstanced in the matter of the sanitation of their camps than the uninoculated. No detailed data for the determination of this question are at present available. But this will be seen to be unimportant, in view, first, of the fact that there was in each regiment and corps an uninoculated majority who must equally with the inoculated have benefited or suffered from the sanitary or insanitary condition of the various camps; and, secondly, of the fact that the inoculated who were attacked were drawn from 12 different corps and regiments. It may therefore be assumed that the inoculated and uninoculated were equally exposed to the risk of infection.

The question as to whether there were any circumstances which tended unduly to swell the roll of typhoid fever among the inoculated is one wbich requires to be treated at somewhat greater length. The following points must be kept in view :-1. So far as is known the men who are set down as inoculated were with hardly an exception only once inoculated. It seems probable from the fact that only two cases among twice inoculated persons have as yet come to my knowledge that second inoculation confers a considerable additional protection. 2. It is possible that certain of the officers who are set down as inoculated may have been inoculated with anti-typhoid serum and not with a vaccine consisting of a sterilised typhoid culture. Two or three instances have been reported to me where this error was committed in the case of officers proceeding to South Africa. In the statistics now in question the date and place o: inoculation are in the case of five out of the nine officers attacked set down as unknown. 3. It is possible in the case of the men as distinguished from the officers that re-vaccination against small-pox, which, like anti-enteric inoculation, was in many cases carried out on board the transports may in certain instances have been confused with the latter inoculation. Instances of this confusion have already several times come to my knowledge. 4. Lastly, it is possible that owing to the exigencies of military service or owing to other reasons the full prescribed dose of typhoid vaccine may not in all cases have been irjected. Instances of the employment of the vaccine in fourfold reduced doses have come to my knowledge. It is conceivable, but there is nothing either to support or rebut the suggestion, that some reduction of the dose may have been found necessary in the case of the Liverpool Regiment, which was inoculated (presumably, as in the case of other regiments, only very partially inoculated) at Ladysmith on the eve of the outbreak of hostilities. At any rate, it is noticeable that this regiment furnished 13 cases of enteric fever among the inoculated men, whereas the whole rest of the garrison of Ladysmith furnished only an equal number of such cases.

In view of the above points, regarding which there is not at present any information available, it is at present impossible to determine precisely to what extent the inoculated were protected by inoculation. But the results set forth in Table I. would appear to be distinctly encouraging, inasmuch as they show that the proportion, on the one hand, of attacks, and on the other band of deaths, from typhoid fever was seven times smaller in the inocnlated than in the uninoculated. And it may be borne in mind that if the number (no doubt a considerable one) of men who had previously suffered from typhoid fever bad been subtracted from the number of the uninoculated, as might quite legitimately have been done, the statistics would have borne an even more favourable aspect.

Netley 


\section{ILLUSTRATIONS OF VASECTOMY OBLITERATION OF THE SEMINAL DUCTS RELATIVE TO HYPER- TROPHY OF THE PROSTATE AND BLADDER ATONY. \\ BY REGINALD HARRISON, F.R.C.S. ENG.,} SURGEON TO ST. PETER'S HOSPITAL.

WHEN sufficient grounds were furnished for asserting that the nutrition and growth of the prostate whether normal or hypertrophied might be importantly influenced by obliteration of the seminal ducts or by removal of the testes ${ }^{3}$ the first stage may be said to have been reached in a series of observations which will probably prove of increasing value in practical surgery. Though experience is not yet suffciently ripe upon this point there are good reasons for believing that a vasectomised or castrated male is not liable to undergo hypertrophy of the prostate in the ordinary acceptation of the term. As this point, as now seems probable, becomes more fully determined not only will a fact of great pathological importance be established, but it will be possible to indicate how by means of a simple and safe operation one of the most serious troubles of advanced life may be averted or controlled. I have reserved for this paper some illustrations of vasectomy or, more strictly speaking, of obliteration of the seminal ducts by torsion, as described in my last articles, ${ }^{2}$ in its application to the treatment of prostatic hypertrophy. Statistical information gathered from the mere collection of a number of cases having but little in common is not of much assistance in a matter of this kind where the con. ditions and circumstances are so varied. In taking my results of vasectomy I find they permit of being grouped as follows: First, where the effects are known to have been good, sufficient, and enduring; secondly, where they have been good but restricted to certain conditions; and, thirdly, where they are alleged to have been inadequate or negative. The question of mortality arising from the operation is not one requiring consideration, as in the series of over 100 cases referred to previously ${ }^{3}$ I stated that I have never seen harm follow.

The first group may be said to include cases of prostatic obstruction pure and simple without any other structural complication. Here the bladder is in no sense secondarily implicated structurally and is capable on the removal of the obstacle in front of it of both holding and expelling its contents. It is in this class of cases that shrinkage of the enlarged prostate, however induced, speedily leads to the restoration of the function of micturition in the fullest sense of the term. This group is best illustrated by cases where for some special or pressing reason the obliteration of the vasa was brought about at an earlier period in the history of prostatic obstruction than is usual. Hence this group is less numerous than the succeeding one where catheter life or the systematic use of this instrument had been resorted to previously. The following cases are selected.

A man, aged 68 years, who was seen in 1896, was suffering from the ordinary symptoms of enlarged prostate-namely, frequent micturition, more especially at night, some degree of residual urine, and occasionally incontinence, the diagnosis being confirmed by rectal examination. He had been advised to use a catheter but could not do so conveniently as he bad lost an arm. Double vasectomy was performed, with an interval of 10 days between each section. I saw him nearly three years afterwards; the prostate was reduced in size. He was quite well and had no occasion for the catheter.

About the same time I divided the vasa of a man, aged 65 years, whose work was greatly interfered with by frequency of micturition due to enlarged prostate. He also had been advised to use a catheter. He was treated in the same way as the patient in the preceding case with a similar result and was examined 18 months afterwards.

In 1897 I saw a man, aged 65 years, who in the course of his occupation travelled much by railway and otherwise. He had an enlarged prostate and much frequency of micturition for which he was advised to use a catbeter. As this

1 Surgery of the Hypertrophied Prostate, by Dr. J. W. White, Trans actions of the American Surgical Association, 1893

The Laycet Auguat 5th, 1899, p. 331, and Mar 5th, 1900, p. 1275. THE LANCET, May 5 th, 1900, p. 1275 meant giving up his livelihood vasectomy was practised with good results and 18 months afterwards he reported himself as being quite well without requiring the catheter.

Early in $1898 \mathrm{I}$ saw a patient in consultation in whose case it had been necessary to tie in a catheter for retention of urine caused by a large prostate. This was so intolerable to him that I suggested vasectomy, which was performed. I have beard on several occasions that he still remains in good health and is able to urinate normally. Six months after the operation I found the prostate much reduced in size.

In 1893 I operated upon a man, aged 67 years, for stone by litholapaxy. There was also some enlargement of the prostate. He remained well till 1897 when symptoms of considerabie enlargement developed, and though he had no recurrence of stone he gradually became entirely dependent upon the catheter and was liable on slight provocation to a tutacks of cystitis and epididymitis. The frequent use of the catheter greatly interfered with his capacity and desire for an active outdoor life and he was compelled to give up hunting and other exercises. In 1898 I divided both his vasa in the usual way with the result that his prostate symptoms gradually disappeared and he resumed his hunting during the whole of last winter as he had previously done. He was able to give up his catheter, using it once in the 24 hours for washing out. He had accustomed himself to the latter as a precautionary method against stone, and though the process, he admitted, was hardly necessary he did not like to give it up.

This appears to be the first published series of cases of prostatic hypertrophy treated by operation in which the object of preserving the normal function of micturition as opposed to an artificial one as illustrated by what is known as catheter life, has been successfully demonstrated. Before leaving this group I would observe that in every case it was explained that the section or division of the vasa might interfere with sexual possibilities. It may, I think, be claimed that in all these instances, and in others that might be mentioned, whatever influence, if any, was exercised on the sexual act the natural function of micturition was preserved to the person operated on and the necessity for the permanent use of a catheter averted. When any question has arisen under these circumstances, so far as my experience goes, relative to whether the urinary or the sexual function should receive first and paramount consideration it has invariably been decided by the patient in favour of the former.

I pass to the second group of cases where I have described the effects following as being good but restricted to certain conditions. These include instances where structural changes in the bladder have supervened upon prostatic obstruction and where catheter life, or the necessity for it, has been more or less developed. This group provides by far the greater proportion of cases to which this class of onerations has been recently applied. In a previous paper ${ }^{4} \mathbf{I}$ showed that there were certain structural effects which followed in the wake of prostatic and other forms of obstruction to the escape of urine by the natural passage which were irrecoverable from. These have reference to the bladder as a reservoir capable of self-expulsion. Hence in the consideration of the class of operations of which vasectomy is a type cause and effect must not be confused. The prostate may be rendered in these ways incapable of obstruction any longer, but this by no means implies that the kladder can be made to expel. And yet the realisation of the former by these means has in this way proved in many instances, which I will proceed to illustate, an inestimable boon.

In November, 1895, I operated on a man, aged 70 years, with a very large prostate and increasing difficulty in catheterism which sometimes required hot baths and opiates before it could be effected. He had shaky hands which increased the difficulty. I advised a double vasectomy. 12 months after this he wrote to me: "I certainly am very much better than I was before the operation, and so long as I am quiet and able to carry out my regular treatment I get on very comfortably."

Anotber case was that of a man, aged 75 years, with a very large prostate and increasing difficulty in passing his instrument. Double vasectomy was performed in 1898. He soon found that he could pass his catheter quite easily and he again wintered abroad last year with much comfort. $\mathrm{He}$ had been previously obliged to forego this change by reason of catheter difficulties.

A man, over 60 years of age, whom I saw in consultation 